\title{
Trade strategies to mitigate the global impact of regional wheat production shocks
}

\author{
P. Golding ${ }^{\text {a }}$, S. Kapadia ${ }^{\text {a }}$, S. Naylor ${ }^{\text {a }}$, J. Schulz ${ }^{\text {a }}, \underline{\text { H.R. Maier }}^{\text {a }}{ }^{(\mathbb{D})}$, U. Lall $^{\text {b }}$ and M. van der Velde ${ }^{c}$ (it) \\ ${ }^{a}$ School of Civil, Environmental \& Mining Engineering, University of Adelaide, Adelaide, South Australia, ${ }^{b}$ \\ Department of Earth and Environmental Engineering, Columbia University, New York, NY, USA, ${ }^{c}$ European \\ Commission, Joint Research Centre, 21027 Ispra, Italy \\ Email:holger.maier@adelaide.edu.au
}

\begin{abstract}
Shocks in regional wheat production can have severe repercussions for dependent importing countries elsewhere. Impacts due to climate extremes, natural disasters, but also (subsequent) export restrictions, reduce volumes of crop produce on international markets that can jeopardize local to national food security. In this manuscript, we consider the capacity of the global wheat trading network to absorb such shocks and identify the trade links between exporting and importing countries that are critical to do so.
\end{abstract}

We specifically consider two questions:

1. Without changing current trade links, can quantities traded be altered to improve the adaptive capacity of the global trade network to mitigate the impact of shocks?

2. In the event of various shocks, which trade links must be versatile to ensure optimal reduction of global wheat deficit?

We impose wheat production shocks in Eastern Europe and Russia, the USA, and Australia to simulate shocks in line with historic events. Assuming that increased prices would stimulate exporting countries to tap into their storage after satisfying domestic demand, we evaluate the most important trade links to optimally reduce the global wheat deficit. As such, we employ ant colony optimisation to reduce the global wheat deficit caused by the regional shocks. The ease with which different trade strategies can be implemented in practice is also considered. Countries cannot establish new trading links but can alter traded amounts. Thus, the minimum global deviation of estimated current traded quantitities is also minimised. The decision variables considered in the optimisation problem are the volumetric tradable quantities of wheat between countries, which allows for consideration of alternative trading strategies on a global scale. Two cases were considered, 1) all countries were able to access their initial storage, in all shock scenarios, to assist in the global reduction of deficit; 2) Russia, the largest exporter, was disallowed access to its storage for export purposes in accordance with historic requirements.

We find that the current global trade network could not completely mitigate the deficit incurred as a result of the simulated shock. However, by redistributing trade quantities on existing trade links, the deficit was reduced considerably in all scenarios. Out of 619 trade links considered, 240 were found to be directly used in achieving minimum deficit solutions. However, while there is significant benefit in increasing the number of active trade links initially, this benefit diminishes towards the lower end of global deficit values. Activating the 30 most important trade links accounted for reducing the global wheat deficit in all scenarios by 80 to $95 \%$.

The study examines the (theoretical) ability of the trade network as a whole to mitigate the impact of shocks. Importing countries with only a few trading partners are at risk to wheat production shock occurring in those exporting countries. In addition, countries that are generally reliant on a variety of suppliers, but come to rely on a single supplier after a shock elsewhere, may find it difficult to increase their import if only low volumes were traded previously. The interplay of a production shock in one region, and a withdrawal from the global wheat market in another region in response to this, can lead to unexpected consequences. Barring access to this country's storage, can affect more countries than solely those directly trading with this country due to the overall network properties. In our analysis, influential exporting countries were those characterized by their ability to alleviate the shock incurred, which depends both on their interconnectivity with affected countries and the amount they have in storage.

Keywords: Global food security, shocks, trade, wheat, ant colony optimisation 


\section{INTRODUCTION}

Short-term, high-impact 'shocks' to the global food network, due to climate extremes, natural disasters or war, can have devastating effects on regional crop production (Puma et al., 2015). In the wake of the 2008 food crisis (e.g. Tadesse et al., 2014), several efforts have focussed on better understanding the role of trade in the context of global food security. For instance, international trade networks were found to decrease inequality in the availability of food relative to domestic production by $25-33 \%$ (Carr et al., 2016).

Of particular interest is the capacity of trade networks to absorb domestic production shortfalls. So far, relatively few attempts have been made to model the impact of short term shocks to the supply side of the global food system (but see Heslin et al., 2020). The global food system evolved with an increasing connectivity and volume of trade flows from 1992-2009 (Puma et al., 2015). This has made the global food system vulnerable to systemic disruptions, and has especially exposed least developed countries to import losses (Puma et al., 2015). A large import dependency will expose a country or region to supply shock elsewhere (Bren d'Amour et al. 2016). Besides the capacity to trade, the size of the domestic per-capita food reserve (relative to import dependency) results in a particular vulnerability to food insecurity (Laio et al., 2016). Similarly, stocks-to-use ratios provide complimentary information to price data as indicators of vulnerability to shortages and price spikes in the global cereal market (Bobenrieth et al., 2013). Marchand et al. (2016) showed how the propagation of domestic food production shocks through the trade network depend on both trade links as well as the distribution of food reserves.

In view of possible global systemic risk to the global food system (Puma et al., 2015), understanding and possibly better managing global trade connectivity is a prerequisite. The improved exchange of information on expected crop production levels, as is done through AMIS (Agricultural Market Information System, http://www.amis-outlook.org/), can contribute to this. Here, we focus on distribution-related options, including improved supply networks (Puma et al., 2015). Overall, we are interested in better understanding the range of (near-) optimal trade strategies available to importing countries in response to regional production shocks elsewhere. Our focus is on mitigating the impact of wheat production shocks occurring in different regions in the world. Wheat is globally significant, as it is the crop grown on the broadest scale (GCARD, 2012) and accounts for $21 \%$ of global food products (Ortiz et al., 2008). We determine the optimal trade response to regional shocks to global wheat production in order to minimise both direct and indirect food shortages in affected countries. We specifically consider two questions:

1. Without changing current trade links, can the quantities traded be altered to improve the adaptive capacity of the global trade network to mitigate the impact of shocks?

2. In the event of various shocks, which trade links must be versatile to ensure optimal reduction of global wheat deficit?

This study provides insight into the utility of using trade as a strategy for mitigating the global impacts of large regional shocks to wheat production.

\section{METHODOLOGY}

\subsection{Optimisation approach}

The aim of distribution-focussed mitigation using trade is to minimise the global wheat deficit caused by localised shocks to crop availability. Consequently optimisation methods can be used to identify a diverse range of trade strategies that are best able to reduce the impact of localised shocks to food security. The decision variables considered in the optimisation problem are the volumetric tradable quantities of wheat between countries, which allows for consideration of alternative trading strategies on a global scale. For any given trade link in a given year, trading patterns are represented as the crop quantities traded from an exporting country to an importing country.

In addition to minimising the global wheat deficit, the ease with which different trade strategies can be implemented in practice is also considered, as this is likely to vary significantly between solutions. For example, alteration of the amount of wheat traded as part of existing agreements is likely to be more easily achievable from a practical perspective than negotiating new trade agreements. Similarly, altering fewer trade agreements and making smaller changes to existing trade agreements is likely to be more practical than altering a larger number of trade agreements or altering agreements by larger amounts. Drastic changes to existing trade arrangements might also be difficult to achieve due to political tensions and cultural differences. Consequently, as there is a trade-off between the ability of countries to satisfy their demand for food in response to the impact of localised shocks and the extent of the changes that have to be made to current trade regimes 
to achieve this, one of the key aims of the optimisation process is to identify solutions that provide different trade-offs between the degree to which global crop deficit can be reduced and the practicality of the solutions in terms of their deviation from current trade arrangements and quantities.

The capacity of some countries to assist with alleviating deficits in other countries through trade is a function of excess supply in a given year, as well as storage from the previous year, and drives the allocation of available tradeable quantities. Subsequently, as storage is a function of the excess supply, it includes the export and import decisions of that country, as well as its production and consumption. Whether a country was considered as exporting or importing was determined with the aid of the Food and Agricultural Organisation's Statistics Division (FAOSTAT) trading data from 2011.

When considering trade as a mitigation option, the decision variables are the volumetric tradable quantities between countries, which allows for consideration of alternative trading strategies on a global scale. For any given trade link in a given year, trading patterns, represented as the crop quantities traded from an exporting country to an importing country are organised in a trade matrix, as represented in Puma et al. (2015). As part of the optimisation process, ant colony optimisation is used to identify the trade routes that minimise the global crop deficit, as well as the global deviation from the known or estimated current traded quantities. The mathematical formulation of the above optimisation problem is given in Golding et al. (2017), as are details of the ant colony optimisation approach (di Matteo et al., 2017, 2019; Maier et al., 2019) used to solve the problem.

\subsection{Data}

Global wheat trade were obtained from FAOSTAT. Foods containing wheat in products such as bread were omitted due to their inability to be substituted by weight and their shorter storage lifespan, which results in minimal international trading of such products. In accordance with FAOSTAT's regional guidelines, 21 of the known 22 exporting countries (exc. Zambia) were grouped into seven regions. Following this regional grouping, we thus consider shocks to occur in spatially-near countries forming each of the seven regions. Such shocks can be caused by extreme climatic events such as droughts. Regional wheat production shock scenarios

In order to test how distribution-focussed management can improve the security of wheat in the event of various shocks, the following approach was sued. Three regions where identified for the origin of shocks, namely North America, Australia and Russia and Eastern Europe. The FAO data for wheat (in mega-tonnes (MT)) were used to define the shocks for each region. For North America, a deficit of $24.75 \mathrm{MT}$ in production was used, corresponding to the worst production year recorded by FAOSTAT between 2000 and 2011. The other shocks were defined in a similar way. Each selected shock has a different global impact, with deficits ranging from 12.04 MT in Australia to 24.75 MT in North America, as shown in Table 1.

Table 1. Global impact of each shock scenario

\begin{tabular}{|l|c|c|c|}
\hline Shock Region & Shock Deficit (MT) (1) & Number of Impacted Countries (2) & Ratio (1)/(2) \\
\hline North America & 24.75 & 88 & 0.28 \\
\hline Australia & 12.04 & 48 & 0.25 \\
\hline Russia / Eastern Europe & 12.86 & 82 & 0.16 \\
\hline
\end{tabular}

The ratio of export reduction to the number of reliant countries is used as a measure of shock significance, with the results shown in descending order in Table 1 . This ratio provides the megaton impact per country known to trade with the exporting countries experiencing shock. These metrics give an insight into the global significance of each shock scenario, and assist in the interpretation of the final results produced from the simulations. Figure 1 shows the global impact of these shocks, where green is representative of the exporting countries, directly impacted by the shock, and red the importing countries indirectly affected by the loss of trade. As can be seen, local shocks can induce significant wheat reductions throughout the global wheat trade network. Grey is representative of the countries who are not connected to the exporting countries experiencing shock. Overall, North America exports significant quantities to 74 countries, making it the region with the largest export reach.

Two cases were considered to explore the ability of the global trade network to respond to shocks. For the first case, all countries were able to access their initial storage, in all shock scenarios, to assist in the global reduction of deficit. For the second case, Russia, the largest exporter, was disallowed access to its storage for export purposes. Case 2 was implemented to investigate the ability of the trade link network to adapt when a large exporter chooses not to utilise its storage in the reduction of global deficit. Russia seemingly stores $87 \%$ of the quantity it exports in excess to the amount it trades, resulting in an initial storage value of $12.6 \mathrm{MT}$. This value 
represents $35 \%$ of the overall storage quantities available to be traded to mitigate regional shocks, and is greater than the impact of all of the regional shocks considered, except for the North American shock. Consequently, Case 2 is likely to provide valuable insight into the impact of removing an exporting country's decision to trade from within its storage.

North America

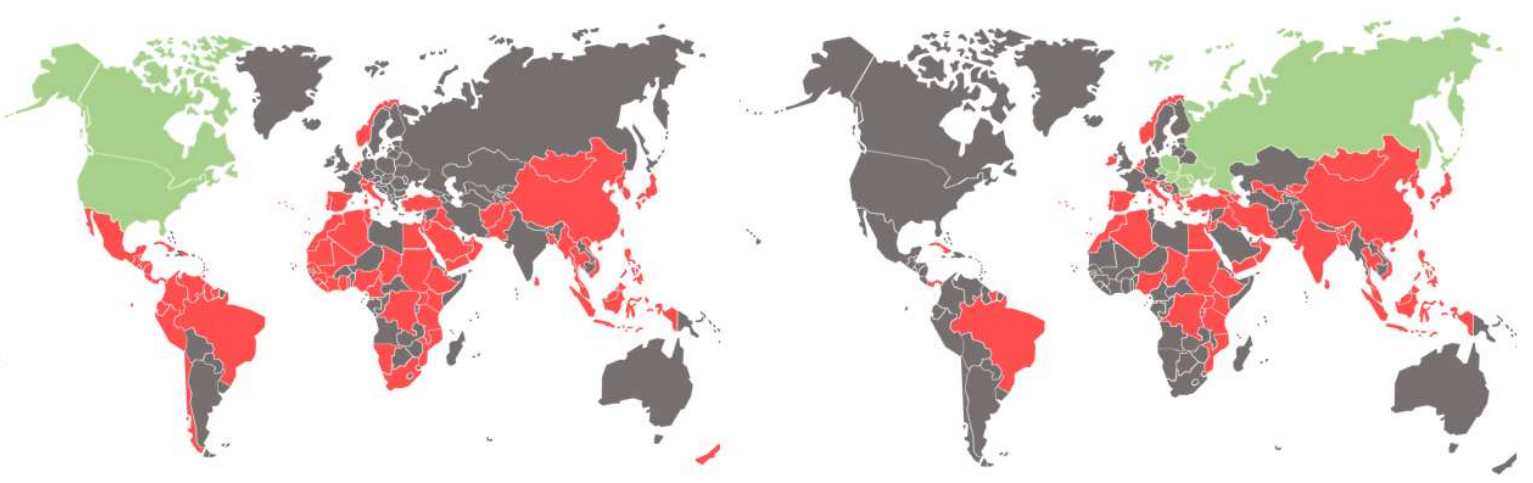

Australia

Regional Shock Applied

Importing Countries Impacted

Not Considered

\section{Eastern Europe}

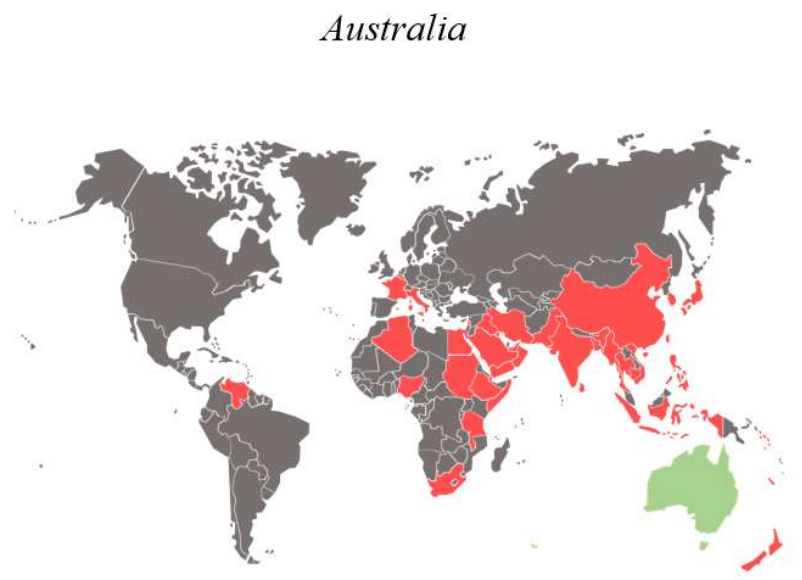

Figure 1. Geographical distribution of shock scenarios

\section{RESULTS AND DISCUSSION}

\subsection{Trade-off between global deficit and number of activated trade links}

Figure 2 demonstrates the trade-off between global deficit and number of activated trade links. As can be seen, the current global trade network is not sufficient to completely mitigate the deficit incurred as a result of the simulated shock. Furthermore, for each of the shocks, the results imply that the global trade structure cannot rely solely on supplies in storage to alleviate the deficit, and a redistribution of existing trade quantities is required to achieve the minimum global deficit values found. The results also show that a greater number of activated trade links is required to achieve lower levels of global deficit. In many cases, it can be seen that a range in the number of activated trade links can achieve a similar reduction in deficit. Similarly, a range of global deficits can be achieved from the same number of activated trade links. This highlights an element of redundancy to a number of the solutions presented identified as part of the optimization process.

For the Case 1 and Case 2 analyses for both the Australian and North American shocks, it can be seen that the marginal return in activating a greater number of trade links remains relatively consistent up until the lower deficit solutions. This suggests that there is significant benefit in increasing the number of active trade links initially, but that this benefit diminishes towards the lower end of global deficit values. For the Eastern European shock, however, a more abrupt trade-off is noticed when moving from six active trade links to seven. Beyond seven active trade links, the improvement in global deficit is marginal. Seven importing countries experience $62 \%$ of the deficit induced by the Eastern European shock. This means that the deficit can be 
reduced significantly through the increase of the amount traded to these seven countries, all of which form important trade links with at least one influential country, aside from Russia. It can also be seen that the spread of solutions is less for Case 2 than it is for Case 1, when examining the Australian and North American shocks. As the potential for Russia to form activated trade links was reduced, when it was not allowed to access its storage, the number of possible trade regimes that correspond to either the deficit or number of activated trade links decreased.

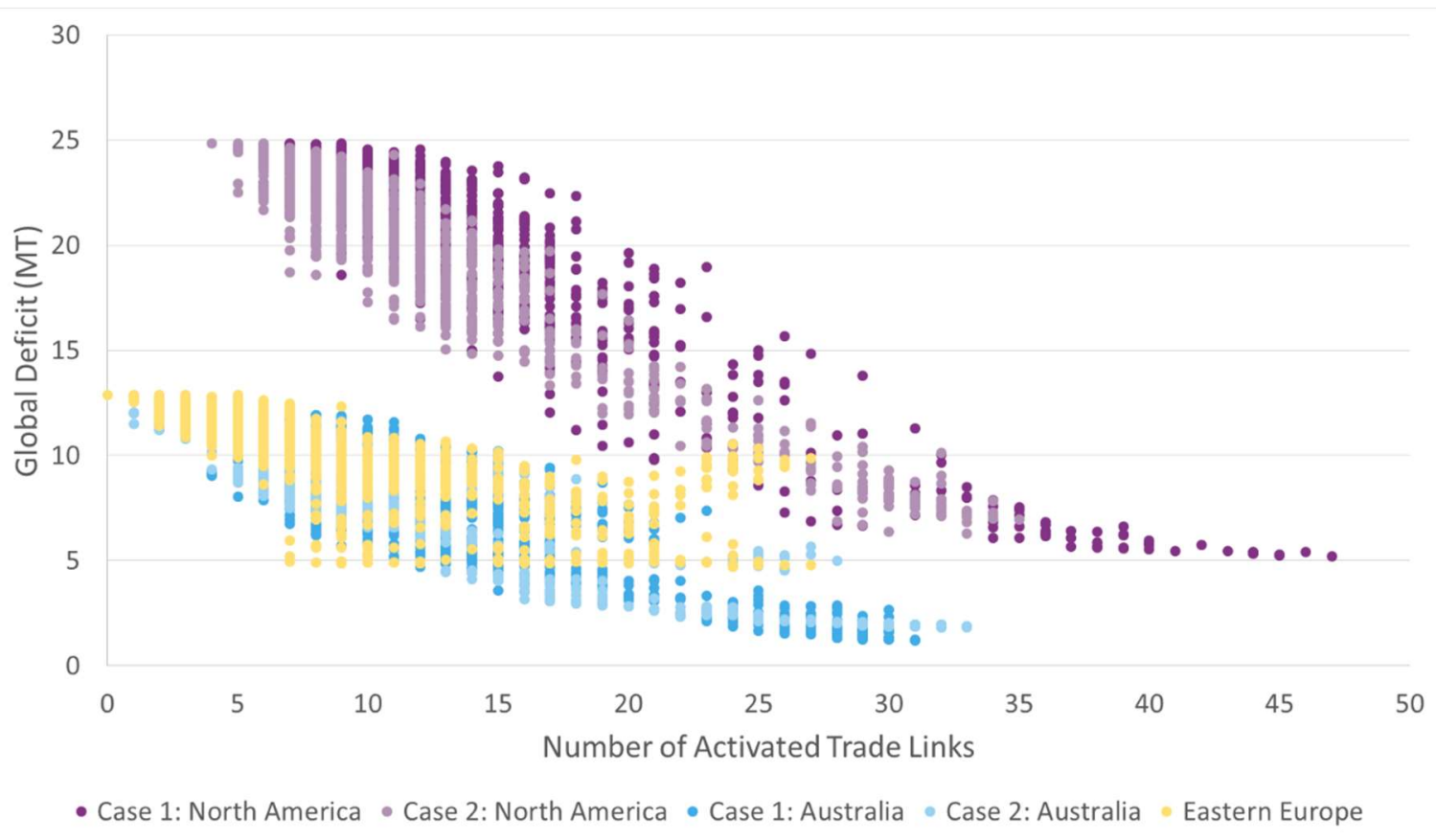

Figure 2. Global deficits for a range of different solutions represented by the number of activated trade links for all shock scenarios

\subsection{Trade links of greatest direct importance for the reduction of global wheat deficit}

In total, 240 trade links were found to be directly used in achieving the minimum deficit solutions. Error! Reference source not found. 3 shows the 30 trade links with greatest direct importance. The thickness of an arrow is proportional to the trade link's direct importance, where a wide arrow represents high levels of direct importance. Exporting countries are denoted by grey nodes, while importing countries are red. The sizes of the importing nodes, themselves, are proportional to the total number of trade links utilised, including those that do not rank within the top 30 and are, therefore, not presented below. The number of directly important links an exporting country forms is representative of its importance overall in mitigating the deficit.

In general, the results suggest that it is more beneficial that countries with smaller nodes form one directly important trade link, while those with more extensive trade structure draw from multiple countries. Figure 3 shows that importing countries with a limited trade network (Mexico, Venezuela, and Peru) form one major link, whereas countries with a more extensive trade network (Bangladesh, Nigeria, Italy, and Egypt) form multiple trade links. There are exceptions, however, with the most obvious being Vietnam. This can be explained by its lower associated import required, where Vietnam requires only 0.18 MT compared to Bangladesh, which has the next lowest requirement at 3.02 MT.

An average of 56 trade links were found to experience growth across the 619 trade links considered, where the average growth was equal to $0.15 \mathrm{MT}$. For the thirty trade links presented in Figure 3, the average growth was significant at $0.58 \mathrm{MT}$. While the primary focus, here, is to understand those trade links with greatest direct importance, an understanding of the traded volumes behind these links, and their consistency of growth across the shocks, provides valuable insight for suggesting changes that could benefit the globe in mitigating deficit.

Of the thirty trade links of greatest direct importance, Figure 3 shows that the connections formed from Russia and Germany had the largest influence on the minimisation of deficit across all three regional shocks, highlighting their significance in the global trade network. Some importing countries utilised a number of large quantity trade links to mitigate their deficit, such as China, while others employed one primary trade link to mitigate their deficit, such as Indonesia. This finding suggests that the mitigation of global deficit is not as 
simple as importing countries extracting as much as they can from their associated exporters, but involves a careful balance between the quantity an exporting country has available and the number of countries dependent on it to mitigate their individual deficits.

The trade link with greatest direct importance, represented by the thickest arrow in Figure 3, was that between Germany and Bangladesh. Bangladesh increased the quantity imported from Germany by 0.17 MT, 0.28 MT, $0.33 \mathrm{MT}$ in the North American, Australian and Eastern European shocks, respectively, making it the only connection found to increase across all scenario experiments. Such consistency suggests that it would be beneficial for Bangladesh to maintain and develop its connection with Germany to ensure that in the event of a shock, it is still able to satisfy its demand.

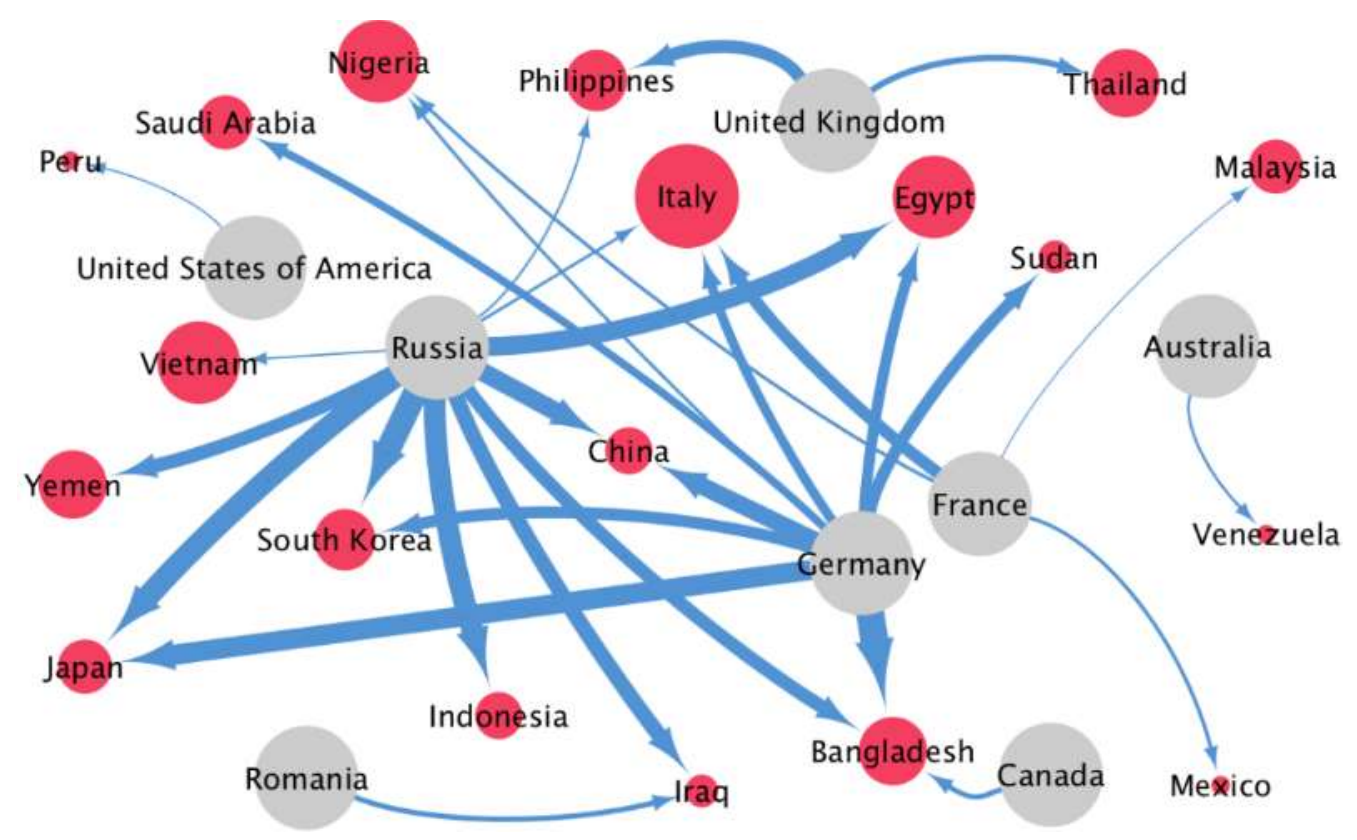

Figure 3. The 30 most directly important trade links across all of the three key shocks

Similar conclusions were found by Heslin et al., 2020. In simulating a US wheat production shock equivalent to the Dust Bowl, they found that impacts of such a production decline outside of the US strongly depended on a country's reserves and relative position in the global trade network.

\section{SUMMARY AND CONCLUSIONS}

Even though determining the near-optimal trading strategies in response to shocks to the global wheat trading system is a theoretical endeavour, it has practical implications. In fact, the research presented here can be seen as a sensitivity analysis of the ability of the trade network as a whole to mitigate the impact of shocks, highlighting those countries especially resilient or exposed to wheat production shocks for different reasons. The results obtained indicate that importing countries with only a few trading partners are at risk to wheat production shock occurring in those exporting countries. In addition, countries that are generally reliant on a variety of suppliers, but come to rely on a single supplier after a shock elsewhere, may find it difficult to increase their import if only low volumes were traded previously.

The interplay of a production shock in one region, and a withdrawal from the global wheat market in another region in response to this, can lead to unexpected consequences. Barring access to this country's storage, can affect more countries than solely those directly trading with this country due to the overall network properties. In our analysis, influential exporting countries were those characterized by their ability to alleviate the shock incurred, which depends both on their interconnectivity with affected countries and the amount they have in storage. Generally, countries with large storages were found to have an extensive trade network (Russia, Germany, France, UK). Interestingly, the USA, Canada, and Australia, which are all significant exporters, had small initial storage values, limiting their ability to mitigate shocks. Further sensitivities arise in the network when one would consider tele-coupled and synchronous shocks, e.g. due to El Nino (Anderson et al., 2019). 
In general, a greater number of activated trade links is required to achieve lower levels of global deficit. In many cases, it can be seen that a range in the number of activated trade links can achieve a similar reduction in deficit. Similarly, a range of global deficits can be achieved from the same number of activated trade links. This highlights an element of redundancy to a number of the solutions identified by the optimization approach. However, the ability of the system to alleviate the impact of a shock is not solely dependent on the number of activated trade links but, also, the manner in which the quantities are distributed across the trade links.

\section{REFERENCES}

Anderson, W.B, Seager, R., Baethgen, W., Cane, M., You, L., et al., 2019. Synchronous crop failures and climate-forced production variability. Science Advances, 5, 7, eaaw1976.

Bobenrieth, E., Wright, B., 2013. Stocks-to-use ratios and prices as indicators of vulnerability to spikes in global cereal markets, Agricultural Economics, 44, s1, 43-52.

Carr, J., D’Odorico, P., Suweis, S., Seekell, D., 2016. What commodities and countries impact inequality in the global food system?, Environmental Research Letters, 11, 095013.

d'Amour, C., Wenz, L., Kalkuhl, M., Steckel, J.C., Creutzig, F., 2016. Teleconnected food supply shocks. Environmental Research Letters, 11, 035007.

Di Matteo M., Dandy G.C. and Maier H.R., 2017. A multi-stakeholder portfolio optimization framework applied to stormwater best management practice (BMP) selection, Environmental Modelling and Software, 97, 16-31.

Di Matteo M., Maier H.R. and Dandy G.C., 2019. Many-objective portfolio optimization approach for stormwater management project selection encouraging decision maker buy-in, Environmental Modelling and Software, 111, 340-355.

GCARD, 2012. The wheat initiative - an international research initiative for wheat improvement. Paper presented at Second Global Conference on Agricultural Research for Development, 2012 Punta del Este, Uruguay.

Golding P., Kapadia S., Naylor S., Schulz J., Maier H.R., Lall U. and van der Velde, M., 2017. Framework for minimising the impact of regional shocks on global food security using multi-objective ant colony optimisation, Environmental Modelling and Software, 95, 303-319.

Heslin, A., Puma, M., Marchand, P., Carr, J., Dell'Angelo, J., D’Odorico, P., Gephart, J., Kummu, M., Porkka, M., Cristina Rulli, M., Seekell, D., Suweis, S., Tavoni, A., 2020. Simulating the cascading effects of an extreme agricultural production shock: global implications of a contemporary US dust bowl event, Frontiers in Sustainable Food Systems, 4, 26, 1-12.

Laio, F., Ridolfi, L., D’Odorico, P., 2016. The past and future of food stocks, Environmental Research Letters, 11, 035010.

Maier H.R., Razavi S., Kapelan Z., Matott L.S., Kasprzyk J. and Tolson B.A., 2019. Introductory overview: Optimization using evolutionary algorithms and other metaheuristics, Environmental Modelling and Software, 114, 195-213.

Marchand, P., Carr, J., Dell'Angelo, J., Fader, M., Gephart, J., Kummu, M., Magliocca, N., Porkka, M., Puma, M., Ratajczak, Z., Cristina Rulli, M., Seekell, D., Suweis, S., Tavoni, A., D’Odorico, P., 2016. Reserves and trade jointly determine exposure to food supply shocks, Environmental Research Letters, 11, 095009.

Ortiz, R., Sayre, K., Govaerts, B., Gupta, R., Subbarao, G., Ban, T., Hodson, D., Dixon, J., Ivan OrtizMonasterio, J., Reynolds, D., 2008. Climate change: can wheat beat the heat?, Agriculture Ecosystems \& Environment, 126, 46-58.

Puma, M., Bose, S., Young Chon, S., Cook, B., 2015. Assessing the evolving fragility of the global food system, Environmental Research Letters, 10, 024007.

Tadesse, G., Algieri, B., Kalkuhl, M., von Braun, J., 2014. Drivers and triggers of international food price spikes and volatility, Food Policy, 47, 117-128. 